
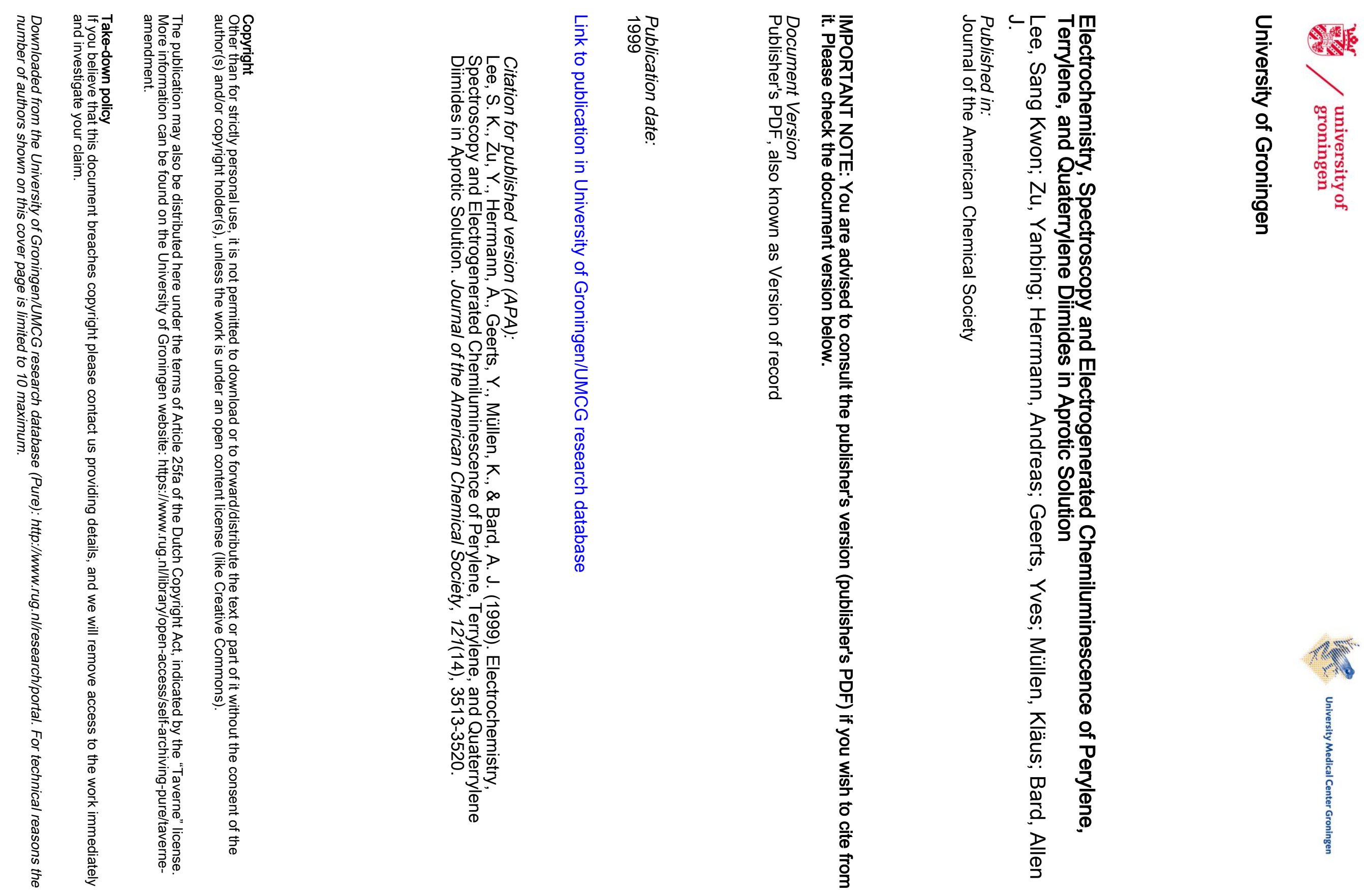

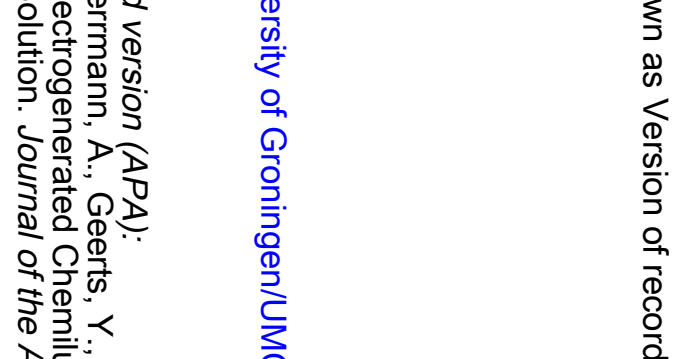
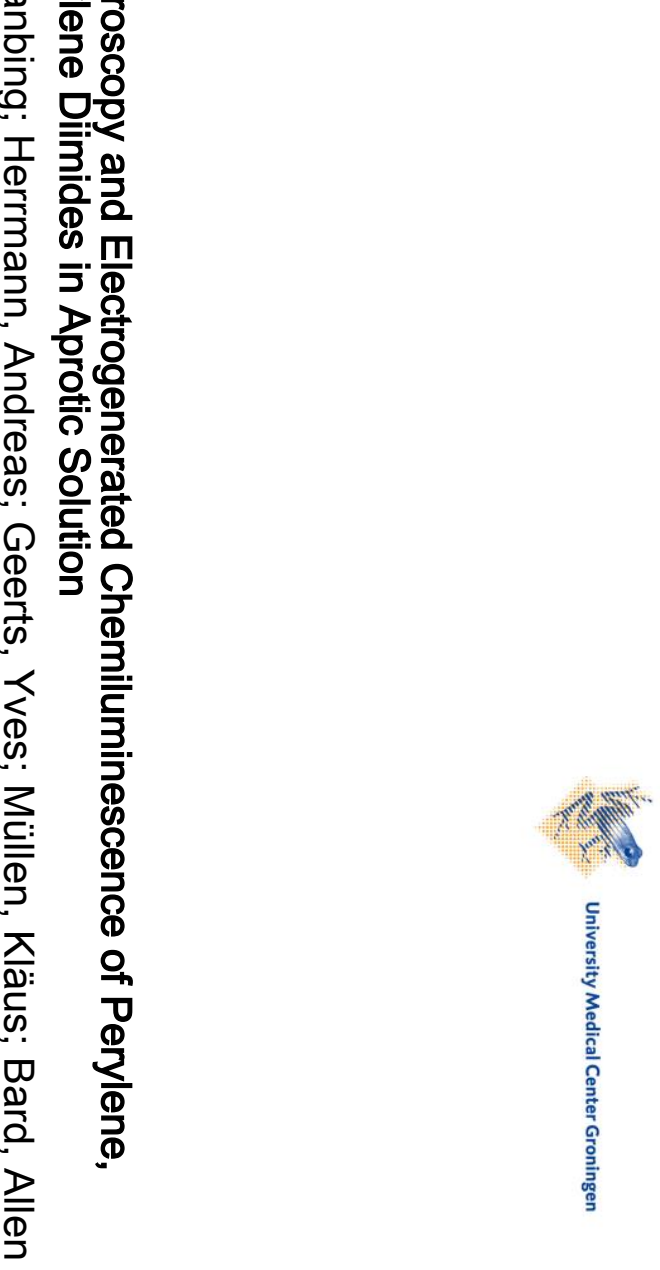


\title{
Electrochemistry, Spectroscopy and Electrogenerated Chemiluminescence of Perylene, Terrylene, and Quaterrylene Diimides in Aprotic Solution
}

\author{
Sang Kwon Lee, ${ }^{\dagger}$ Yanbing Zu, ${ }^{\dagger}$ Andreas Herrmann, ${ }^{\ddagger}$ Yves Geerts, ${ }^{\ddagger}$, Kläus Muillen, ${ }^{\ddagger}$ and \\ Allen J. Bard*, $\dagger$ \\ Contribution from the Department of Chemistry and Biochemistry, The University of Texas at Austin, \\ Austin, Texas 78712, and Max-Planck-Institut für Polymerforschung, Ackermannweg 10, \\ 55128 Mainz, Germany
}

Received December 4, 1998

\begin{abstract}
The electrochemistry, UV-vis spectrophotometry, photoluminescence, and electrogenerated chemiluminescence (ECL) of perylenedicarboxylic imide, perylenetetracarboxylic diimide (PDI), terrylenetetracarboxylic diimide (TDI), and quaterrylenecarboxylic diimide (QDI) were investigated. All compounds undergo two reversible one-electron reductions and one reversible one-electron oxidation reaction. The first reduction potential shifts to less negative values and the potential for oxidation to less positive values for the diimide series with increasing size of the aromatic core. These changes in potential correlate well with orbital energies from molecular orbital calculations. The difference in potential between the first and second reduction waves decreased with increasing distance between the imide groups, so that TDI and QDI show only a single reduction wave, equivalent to a two-electron reduction. These reduction potentials provide estimates for the equilibrium constant for disproportionation of the radical anion. Very stable ECL spectra of PDI or TDI generated by sequential production of the radical cation and radical anion at an electrode were observed; these were identical to the photoluminescence spectra. A consideration of the energetics of the electron transfer reaction and the singlet energy leads to the conclusion that emission occurs mainly via generation of triplets followed by triplettriplet annihilation (the T-route).
\end{abstract}

\section{Introduction}

We describe here the electrochemical reduction and oxidation and radical ion annihilation electrogenerated chemiluminescence (ECL) of perylene, terrylene, and quaterrylene diimides (Figure 1 ) in aprotic solution. We felt that these molecules deserved study on the basis of the stability of their radical ions and the good fluorescence efficiencies of compounds of this series, which suggest good ECL properties. Moreover, as described below, the electrochemistry allows examination of the energetics during the stepwise formation of the radical anion and dianion as a function of molecule size. Of particular interest is the long wavelengths for emission from the diimides compared to the hydrocarbon core, which is of importance in the design of ECL labels that emit in the red and near-IR region.

Perylene dyes have been known since 1913 as highly photostable pigments or vat dyes. Perylenetetracarboxylic diimides have been studied because of their brilliant color, strong absorption and fluorescence, and good thermal, chemical, and photochemical stability. 1,2 They have been suggested as chro-

\footnotetext{
$\dagger$ The University of Texas at Austin.

Max-Planck-Institut für Polymerforschung

$\S$ Present address: Université Libre de Bruxelles, Macromolecular Chemistry, CP 206/1, Boulevard du Triomphe, 1050 Bruxelles, Belgium.

(1) (a) Zolinger, H. Color Chemistry; VCH: New York, 1991. (b) Fabian, J.; Zahradnik, R. Angew. Chem., Int. Ed. Engl. 1989, 28, 677.

(2) (a) Quante, H.; Geerts, Y.; Müllen, K. Chem. Mater. 1997, 9, 495. (b) Quante, H.; Müllen, K. Angew. Chem., Int. Ed. Engl. 1995, 34, 1323. (c) Feiler, L.; Langhals, H.; Polborn, K. Liebigs Ann. 1995, 7, 1229. (d) Demmig, S.; Langhals, H. Chem. Ber. 1988, 121, 225. (e) Langhals, H Chem. Ber. 1985, 118, 4641. (f) Geerts, Y.; Quante, H.; Platz, H.; Mahrt, R.; Hopmeier, M.; Böhm, A.; Müllen, K. J. Mater. Chem., in press.
}

mophores for applications, such as reprographical processes, ${ }^{3}$ fluorescent solar collectors, ${ }^{4}$ photovoltaic devices, ${ }^{5}$ dye lasers,${ }^{6}$ and molecular switches. ${ }^{7,8}$ Recently, several new terrylenetetracarboxylic diimides and quaterrylenetetracarboxylic diimides were synthesized. ${ }^{2 \mathrm{f}, 9}$ Owing to their extended $\pi$ systems, these molecules exhibit absorption and emission bands at much longer wavelengths $\left(\lambda_{\mathrm{ab}}=650-760 \mathrm{~nm}, \lambda_{\mathrm{fl}}=665-780 \mathrm{~nm}\right)$ than the corresponding perylene diimides $\left(\lambda_{\mathrm{ab}}=526 \mathrm{~nm}, \lambda_{\mathrm{fl}}=545 \mathrm{~nm}\right)$; the fluorescence quantum yields of terrylenetetracarboxylic diimides are near 1.0. These characteristics make them good potential ECL labels for analytical purposes.

ECL is initiated by the generation of ions capable of undergoing energetic electron-transfer reactions at electrodes. ${ }^{10}$ The general scheme involves the alternate electrochemical production of radical cations and radical anions (eqs 1 and 2) by stepping the electrode potential to appropriate values. The

(3) Loufty, H. O.; Hor, A. M.; Kazmaler, P.; Tarn, M. J. Imaging Sci. 1989, 33, 151

(4) Seybold, G.; Wagenblast, G. Dyes Pigm. 1989, 11, 303.

(5) Schlettwein, D.; Wöhrle, D.; Karmann E.; Melville, U. Chem. Mater. 1994, $6,3$.

(6) Sadari, M.; Hadel, L.; Sauers, R. R.; Husain, S.; Krogh-Jespersen, K.; Westbrook, J. D.; Bird, G. R. J. Phys. Chem. 1992, 96, 7988.

(7) O’Neil, M. P.; Niemczyk, M. P.; Svec, W. A.; Gosztola, D.; Gaines, G. L.; Wasielewski, M. R. Science 1992, 257, 63.

(8) Tasch, S.; List, E. J. W.; Ekstrom, O.; Graupner, W.; Leising, G. Schlichting, P.; Rohr, U.; Geerts, Y.; Scherf, U.; Müllen, K. Appl. Phys. Lett. 1997, 71, 2883.

(9) Holtrup, F. O.; Müller, G. R. J.; Quante, H.; Feyter, S. D.; Schryver, F. C. D.; Müllen, K. Chem. Eur. J. 1997, 3, 219.

(10) Faulkner, L. R.; Bard, A. J. In Electroanalytical Chemistry; Bard, A. J., Ed.; Marcel Dekker: New York, 1977; Vol. 10, pp 1-95. 
PI

PDI

TDI

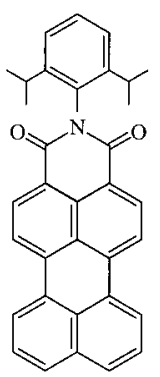<smiles>[R]c1cc([R])c([R4])c([R])c1[R]</smiles><smiles>C=c1c(=O)[nH][nH]c(=O)c1=CC</smiles><smiles>C=C1C(=O)c2ccc3c4c(ccc(c24)/C1=C/C)C(=O)N(C)C3=O</smiles><smiles>[R]c1cc([R])c([R])cc1[R]</smiles>

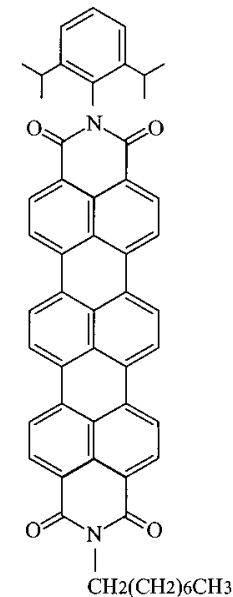

$\mathrm{CH} 2(\mathrm{CH} 2) 6 \mathrm{CH} 3$

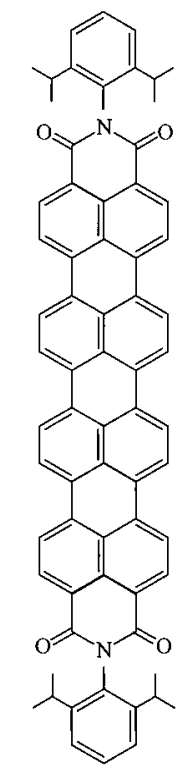

PDI-1: $\mathrm{R}_{1}=\mathrm{R}_{4}=$ methyl, $\mathrm{R}_{2}=\mathrm{R}_{3}=\mathrm{H}$

PDI-2: $\mathrm{R}_{1}=\mathrm{R}_{4}=$ iso-propyl, $\mathrm{R}_{2}=\mathrm{R}_{3}=\mathrm{H}$

PDI-3: $\mathrm{R}_{1}=\mathrm{R}_{3}=\mathrm{H}, \mathrm{R}_{2}=\mathrm{R}_{4}=$ tert -butyl
QDI

Figure 1. Chemical structures used in this investigation: PI, $(2,6-$ diisopropylphenyl)-3,4-perylenedicarboxylic imide; PDI-1, $N, N^{\prime}$-bis(2,6-dimethylphenyl)-3,4,9,10-perylenetetracarboxylic diimide; PDI-2, $N, N^{\prime}$-bis(2,6-diisopropylphenyl)-3,4,9,10-perylenetetracarboxylic diimide; PDI-3, $N, N^{\prime}$-bis(2,5-di-tert-butylphenyl)-3,4,9,10-perylenetetracarboxylic diimide; TDI, $N$-(2,6-diisopropylphenyl)- $N^{\prime}$-octylterrylenetetracarboxylic diimide; QDI, $N, N^{\prime}$-bis(2,6-diisopropylphenyl)-3,4,9,10quaterrylenetetracarboxylic diimide.

subsequent annihilation reaction between these two ions generates excited states that lead to emission (eqs 3 and 4).

$$
\begin{gathered}
\mathrm{R}-\mathrm{e} \rightarrow \mathrm{R}^{\bullet+} \\
\mathrm{R}+\mathrm{e} \rightarrow \mathrm{R}^{{ }^{-}} \\
\mathrm{R}^{\cdot+}+\mathrm{R}^{\cdot-} \rightarrow{ }^{1} \mathrm{R}^{*}+\mathrm{R} \\
{ }^{1} \mathrm{R}^{*} \rightarrow \mathrm{R}+h v
\end{gathered}
$$

In the case of an energy-deficient system, i.e., a system where the enthalpy of the annihilation reaction is smaller than the energy needed to produce the excited singlet, the luminescent singlet state can be produced via the triplet-triplet annihilation reactions (the T-route). ${ }^{10}$

$$
\begin{aligned}
& \mathrm{R}^{\bullet+}+\mathrm{R}^{\bullet-} \rightarrow{ }^{3} \mathrm{R}^{*}+\mathrm{R} \\
& { }^{3} \mathrm{R}^{*}+{ }^{3} \mathrm{R}^{*} \rightarrow{ }^{1} \mathrm{R}^{*}+\mathrm{R}
\end{aligned}
$$

Many polyaromatic hydrocarbons, the first compounds examined for ECL applications, produce emission by this reaction scheme. ${ }^{10-13}$ In particular, the ECL of perylene ${ }^{12}$ and, more recently, dibenzotetraphenylperiflanthene containing a perylene spacer $^{13}$ has been described. There has been one previous

(11) (a) Knight, A. W.; Greenway, G. M. Analyst 1994, 119, 879. (b) Debad, J. D.; Lee, S. K.; Qiao, X.; Pascal, R. A., Jr.; Bard, A. J. Acta Chem. Scand. 1998, 52, 45. (c) Maloy, J. T.; Bard, A. J. J. Am. Chem. Soc. 1971, 93, 5968. (d) Bezman, R.; Faulkner, L. R. J. Am. Chem. Soc. 1972, $94,6324$.

(12) Werner, T. C.; Chang, J.; Hercules, D. M. J. Am. Chem. Soc. 1970, 92,5560 .

(13) (a) Debad, J. D.; Morris, J. C.; Lynch, V.; Magnus, P.; Bard, A. J. J. Am. Chem. Soc. 1996, 118, 2374. (b) Debad, J. D.; Morris, J. C.; Magnus, P.; Bard, A. J. J. Org. Chem. 1997, 62, 530.

report briefly describing the ECL of two different $N$-substituted perylene diimide compounds. ${ }^{14}$

The species described here are perylenedicarboxylic imide (PI), three perylenetetracarboxylic dimides (PDI-1, -2, and -3), terrylenetetracarboxylic diimide (TDI), and quaterrylenecarboxylic diimide (QDI). The main focus of this study was to correlate the structures of a homologous series of imides of different sizes and orbital energies and their electrochemical properties and ECL. We discuss the effect of the aromatic imide structure and the $N$-substituent on redox potentials and the disproportionation of the radical anions.

\section{Experimental Section}

Chemicals. Acetonitrile (MeCN, UV grade, Burdick and Jackson, Muskegon, MI) and chloroform (anhydrous, 99+\%, Aldrich) were used as received after being transported unopened into an inert atmosphere drybox (Vacuum Atmospheres Corp., Los Angeles, CA). Tetra- $n$ butylammoniom hexafluorophosphate TBAPF $_{6}$, SACHEM, Inc., Austin, TX) was recrystallized from $\mathrm{EtOH} / \mathrm{H}_{2} \mathrm{O}(4: 1, \mathrm{v} / \mathrm{v})$ three times and dried at $100{ }^{\circ} \mathrm{C}$ in a vacuum oven and stored in the drybox before use. All solutions used in UV-vis, fluorescence, electrochemistry, and ECL measurements were prepared in the drybox under a helium atmosphere and sealed in airtight cells.

(2,6-Diisopropylphenyl)-3,4-perylenedicarboxylic imide (PI) (Aldrich), $N, N^{\prime}$-bis(2,6-dimethylphenyl)-3,4,9,10-perylenetetracarboxylic diimide (PDI-1) ( $~ 85 \%$, Aldrich), and $N, N^{\prime}$-bis(2,5-di-tert-butylphenyl)3,4,9,10-perylenetetracarboxylic diimide (PDI-3) ( 97\%, Aldrich) were used as received. $N, N^{\prime}$-Bis(2,6-diisopropylphenyl)-3,4,9,10-perylenetetracarboxylic diimide (PDI-2), $N$-(2,6-diisopropylphenyl)- $N^{\prime}$-octylterrylenetetracarboxylic diimide (TDI), and $N, N^{\prime}$-bis(2,6-diisopropylphenyl)-3,4,9,10-quaterrylenecarboxylic diimide (QDI) were available from previous studies. ${ }^{2 \mathrm{f}, 8,9}$ Deionized water from a Millipore Milli-Q system was used throughout.

Apparatus and Procedures. A charge-coupled device (CCD) camera (Photometrics $\mathrm{CH} 260$ ) cooled to below $-135^{\circ} \mathrm{C}$ and interfaced to a personal computer was used to obtain ECL spectra. The camera was focused on the output of a grating spectrometer (concave grating, $1 \mathrm{~mm}$ entrance slit, Holographics, Inc.). The CCD camera and general configuration of the spectra acquisition have been described previously. ${ }^{15}$

Cyclic voltammetry and bulk electrolysis for spectroelectrochemistry experiments were carried out with either the Model 660 electrochemical workstation (CH Instruments) or a PAR Model 173/175. The working electrode consisted of an inlaid platinum disk (1.5 or $2.1 \mathrm{~mm}$ diameter) that was polished on a felt pad with $0.05 \mu \mathrm{m}$ alumina (Buehler, Ltd.) and sonicated in absolute EtOH for $1 \mathrm{~min}$ before each experiment. A platinum wire was used as a counter electrode. A silver wire served as quasi-reference electrode, and its potential was calibrated vs aqueous SCE (for comparison with earlier studies) by addition of ferrocene as an internal standard (taking $E\left(\mathrm{Fc} / \mathrm{Fc}^{+}\right)=0.424 \mathrm{~V}$ vs SCE in the mixed solvent of $\mathrm{CHCl}_{3} / \mathrm{MeCN}$ ).

Fluorescence spectra were obtained with a SLM Aminco SPF-500 spectrofluorometer, and UV-vis spectra were recorded on a Milton Roy Spectronic 3000 array spectrophotometer.

Calculations. Digital simulation for electrochemical reactions of TDI and QDI utilized DigiSim (BAS, West Lafayette, IN) run on a Gateway 2000 model P5-90 personal computer. The Hyperchem 5.0 software package was used for molecular mechanics and semiempirical molecular orbital calculations. The structures of the compound molecules were optimized using the MM+ force field. Nonbonded electrostatic interactions were calculated using bond dipole interactions. PM3 was chosen as the semiempirical method to calculate the molecular orbitals and electron density at each atom since it has been reported to perform well on peri-fused polycyclic hydrocarbons ${ }^{16}$ and is probably more

(14) Salbeck, J.; Kunkely, H.; Langhals, H.; Saalfrank, R. W.; Daub, J. Chimia 1989, 43, 6.

(15) McCord, P.; Bard, A. J. J. Electroanal. Chem. 1991, 318, 91.

(16) Plummer, B. F.; Steffen, L. K.; Herndon, W. H. Struct. Chem. 1993, $4,279$. 

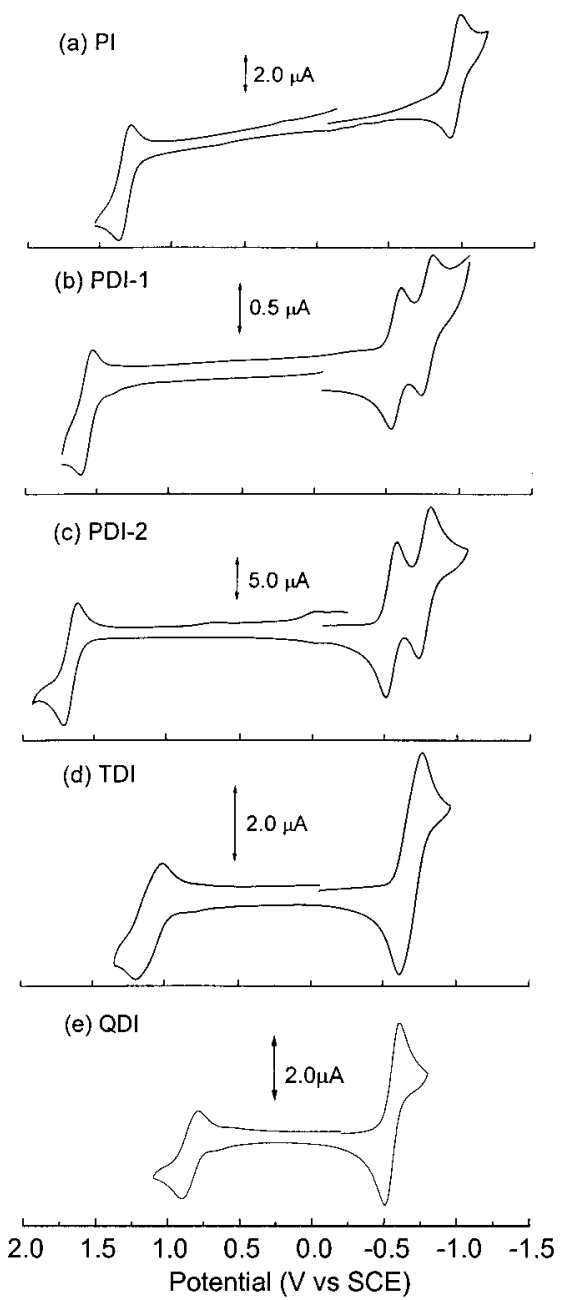

Figure 2. Cyclic voltammograms of (a) $0.8 \mathrm{mM} \mathrm{PI}$ in $\mathrm{CHCl}_{3} / \mathrm{MeCN}$ $(3: 2, \mathrm{v} / \mathrm{v})$, (b) $0.3 \mathrm{mM}$ PDI-1 in $\mathrm{CH}_{3} \mathrm{CN} / \mathrm{MeCN}(2: 1, \mathrm{v} / \mathrm{v})$, (c) $0.8 \mathrm{mM}$ PDI-2 in $\mathrm{CHCl}_{3} / \mathrm{MeCN}(3: 2, \mathrm{v} / \mathrm{v})$, (d) $0.21 \mathrm{mM}$ TDI in $\mathrm{CHCl}_{3} / \mathrm{MeCN}$ $(4: 1, \mathrm{v} / \mathrm{v})$, and (e) $0.1 \mathrm{mM}$ QDI in $\mathrm{CHCl}_{3} / \mathrm{MeCN}(4: 1, \mathrm{v} / \mathrm{v})$. Scan rate: $(\mathrm{a}, \mathrm{b})=0.2 \mathrm{~V} / \mathrm{s} ;(\mathrm{c}-\mathrm{e})=0.5 \mathrm{~V} / \mathrm{s}$ (electrolyte: $\left.0.1 \mathrm{M} \mathrm{TBAPF}_{6}\right)$.

suitable for compounds containing nitrogen and oxygen. ${ }^{17}$ Normal precision was used.

\section{Results and Discussions}

Electrochemistry. Cyclic voltammetry (CV) was used to obtain information about the energetics for formation of the species $\mathrm{R}^{{ }^{-}}, \mathrm{R}^{2-}$, and $\mathrm{R}^{\cdot+}$ and their stability. The chemical structures of the compounds of interest are given in Figure 1. The $\mathrm{CV}$ for these in $\mathrm{CHCl}_{3} / \mathrm{MeCN}$ solutions is shown in Figure 2. The perylene compounds (PDI), at scan rates $(v)$ above 0.2 $\mathrm{V} / \mathrm{s}$, show chemically reversible waves for the stepwise reduction [two one-electron (1e) transfers] and a 1e oxidation. In the cases of TDI and QDI, however, the two-electron (2e) reduction occurs in a single wave, and the oxidation in a 1e wave (about one-half the height of the reduction wave, Figure 2d,e). At scan rates below $0.2 \mathrm{~V} / \mathrm{s}$, for PDI-1 and TDI, the oxidation waves become less reversible, suggesting that the radical cations undergo slow decomposition, although in a previous study of PDI-3 in MeCN, good reversibility was seen at $0.05 \mathrm{~V} / \mathrm{s} .{ }^{14}$ Nevertheless, the radical cation was sufficiently stable for ECL generation, as discussed below. The radical cation of QDI was more stable, and the reversibility of the QDI oxidation wave varied little for scan rates as low as $0.05 \mathrm{~V} / \mathrm{s}$.

(17) HyperChem Release 5.0 for Windows Reference Manual, Hypercube, Inc, Publication HC50-00-02-00, October 1996.
Table 1. Cyclic Voltammetric Results for PI, PDI (-1, -2, -3), TDI, and QDI Compounds ${ }^{a}$

\begin{tabular}{lcccccc}
\hline compd & $\begin{array}{c}E_{1 \mathrm{o}} \\
(\mathrm{V} \text { vs SCE) }\end{array}$ & $\begin{array}{c}E_{1 \mathrm{r}} \\
\text { (V vs SCE) }\end{array}$ & $\begin{array}{c}E_{2 \mathrm{r}} \\
(\mathrm{V} \text { vs SCE) }\end{array}$ & $\begin{array}{c}\Delta E^{\circ} \text { or } \\
(\mathrm{V})\end{array}$ & $\begin{array}{c}\Delta E^{\circ}{ }_{\mathrm{r}} \\
(\mathrm{V})\end{array}$ & $K^{e}$ \\
\hline PI & $1.37^{b}$ & $-1.10^{b}$ & $-1.66^{b}$ & 2.36 & $\sim 0.56$ & $3.1 \times 10^{9}$ \\
PDI-1 & $\left(1.31^{c}\right)$ & $\left(-1.05^{c}\right)$ & - & & & \\
& $1.62^{b}$ & $-0.60^{b}$ & $-0.81^{b}$ & 2.11 & 0.21 & $3.6 \times 10^{3}$ \\
PDI-2 & $\left(1.56^{c}\right)$ & $\left(-0.55^{c}\right)$ & $\left(-0.75^{c}\right)$ & & & \\
& $1.71^{b}$ & $-0.58^{b}$ & $-0.80^{b}$ & 2.18 & 0.22 & $5.3 \times 10^{3}$ \\
PDI-3 & $\left(1.65^{c}\right)$ & $\left(-0.53^{c}\right)$ & $\left(-0.75^{c}\right)$ & & & \\
& $1.76^{b}$ & $-0.55^{b}$ & $-0.79^{b}$ & 2.17 & 0.23 & $7.9 \times 10^{3}$ \\
TDI & $\left(1.677^{c}\right)$ & $\left(-0.50^{c}\right)$ & $\left(-0.73^{c}\right)$ & & & \\
& $1.21^{b}$ & $-0.73^{b}$ & - & 1.75 & 0.07 & 15 \\
QDI & $\left(1.12^{c}\right)$ & $\left(-0.63^{d}\right)$ & $\left(-0.70^{d}\right)$ & & & \\
& $0.88^{b}$ & $-0.62^{b}$ & - & 1.40 & 0.04 & 5 \\
& $\left(0.82^{c}\right)$ & $\left(-0.58^{d}\right)$ & $\left(-0.62^{d}\right)$ & & & \\
\hline
\end{tabular}

${ }^{a}$ Scan rate: $0.2 \mathrm{~V} / \mathrm{s}$ in $\mathrm{CHCl}_{3}: \mathrm{MeCN}$ (see caption, Figure 2 for ratios):0.1 M TBAPF $6 .{ }^{b}$ Peak potential. ${ }^{c}$ Half-wave potential. ${ }^{d}$ Halfwave potential obtained by digital simulation. ${ }^{e}$ Equilibrium constant for comproportion reaction between $\mathrm{R}$ and $\mathrm{R}^{2-}$.

$\mathrm{CV}$ of PI revealed one reversible 1e reduction peak at -1.10 $\mathrm{V}$ vs $\operatorname{SCE}(v=0.2 \mathrm{~V} / \mathrm{s})$ with a second irreversible reduction peak at $-1.66 \mathrm{~V}$. The electrochemistry of PI compared to its parent compound, perylene, reflects the strong electron-accepting nature of the carboximide substituent in PI. Thus, the first $1 \mathrm{e}$ reduction potential of PI is less negative than that of perylene $(-1.68 \mathrm{~V}$ vs SCE $){ }^{18}$

The measured redox potentials for the series of compounds with different aromatic imide structures and $N$-substitutuents are listed in Table 1 . The first reduction potential shifts positively for the imide compounds in the following order: PI < PDI, TDI, and QDI. While there is little effect of the nature of the $\mathrm{N}$-substituent on the reduction potential, a large effect is observed with changes in the aromatic imide structure. The reduction potential of the conjugated hydrocarbon structure reflects the electron affinity of the system. Comparing PDI to PI, the potential of first reduction peak shifts from -1.10 to $-0.60 \mathrm{~V}$, showing that the addition of another imide group to the perylene makes the molecule much easier to reduce. The potential difference between the first and second 1e reduction waves is greatly reduced for PDI, indicating that the addition of the second electron is also much easier with comparison to PI.

With the addition of fused rings and an increase in the distance between the two imide groups, the spacing between the two successive 1e reduction waves decreases until a single 2e wave (for TDI and QDI) results, although the reduction potential of the first wave is not significantly affected. For TDI and QDI, the current of the reduction peak is about twice that of the oxidation peak, suggesting that the potential difference between the first and second 1e reduction waves is greatly reduced and the two peaks completely overlap. This result suggests that in TDI and QDI the electronic charge is largely localized in the imide groups, and there is relatively little interaction between the groups. We discuss this further after the molecular orbital calculations are described. The proposed reduction mechanism for the diimide systems is shown in Scheme 1, where the 1e transfer processes lead to the formation of a radical anion and then the dianion. It is reasonable to assume that the major portion of the electron density resides on the carbonyl oxygen due to the electron-withdrawing nature of the oxygen atom as indicated in possible resonance forms in Scheme 1. For PDI, the addition of the second electron is more difficult than the first because of Coulombic repulsion between the pair

(18) Parker, V. D. J. Am. Chem. Soc. 1976, 98, 98. 
Scheme 1. Proposed Two-Step Reduction Mechanism for the Diimide Molecules

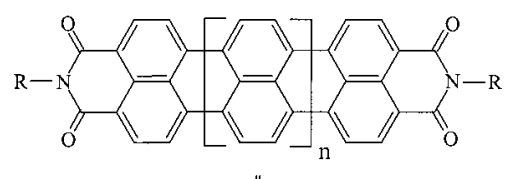

$\mathrm{E} 1, \mathrm{r}$. $\mathrm{e}^{-}$

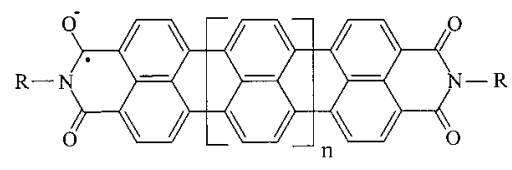

$\mathrm{E} 1, \mathrm{r} \| \mathrm{e}^{-}$

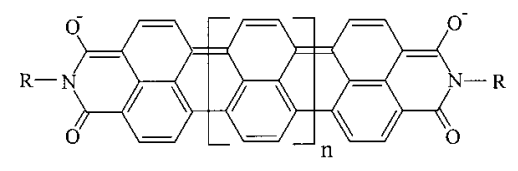

PDI: $\mathrm{n}=0$, TDI: $\mathrm{n}=1$, QDI: $\mathrm{n}=2$.

$\mathrm{R}=$ alkyl or aryl

Scheme 2. Proposed Oxidation Reaction for Generating the Diimide Radical Cation

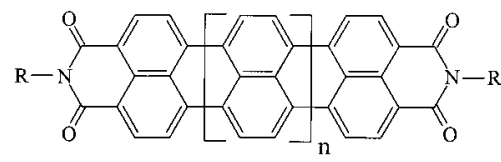

$\mathrm{E} 1, \mathrm{o} \|-\mathrm{e}-$

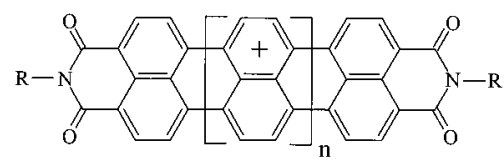

PDI: $\mathrm{n}=0$, TDI: $\mathrm{n}=1$, QDI: $\mathrm{n}=2$.

$\mathrm{R}=$ alkyl or aryl

of electrons interacting through the $\pi$-orbitals of the intervening perylene spacer. The second reduction potential should be affected by the resonance energy and the ability to delocalize the first electron density. The extended aromatic fused rings will increase the resonance energy and delocalize the negative charge more effectively. Therefore, the second 1e reduction potentials become much closer to the first reduction potentials in the case of TDI and QDI, and the Coulombic repulsion in the dianions is rendered weaker. The reduction of the diimide systems gives rise to an increased quinoidal character due to charge separation by the ring structure, which minimizes the electron-electron repulsion. ${ }^{19}$ The dianion form in Scheme 1 is represented by reduced cis-carbonyls. It can also be represented by reduced trans-carbonyls, but this requires the loss of aromaticity in the pery-, terry-, or quaterry-lene spacers.

The proposed 1e oxidation reaction for generation of the diimide radical cation is shown in Scheme 2. The odd electron is delocalized over the system. A comparison of PDI-1, -2, and -3 shows that the $N$-substituents have little influence on the oxidation reaction. In all cases, the $N$-phenyl rings are twisted

(19) Viehbeck, A.; Goldberg, M. J.; Kovac, C. A. J. Electrochem. Soc. $1990,137,1460$.
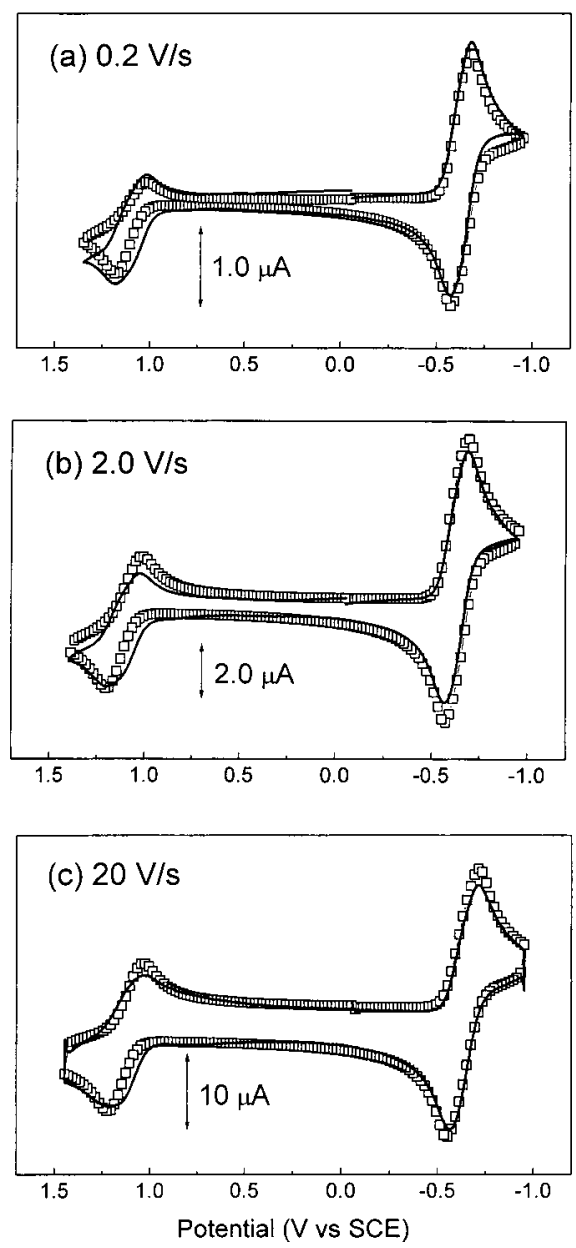

Figure 3. Scan rate variations of cyclic voltammograms by the experimental (-) and digital simulations ( $\square$ ) of $0.21 \mathrm{mM}$ TDI in $\mathrm{CHCl}_{3} /$ $\mathrm{CH}_{3} \mathrm{CN}(4: 1, \mathrm{v} / \mathrm{v})$, (electrolyte: $\left.0.1 \mathrm{M} \mathrm{TBAPF}_{6}\right)$ : (a) $=0.2,(\mathrm{~b})=2.0$, and $(\mathrm{c})=20 \mathrm{~V} / \mathrm{s}$ at a $1.4 \mathrm{~mm}$ diameter Pt electrode. The experimental data were corrected for Ohmic drop. Simulation parameters: reduction reaction $E_{1 \mathrm{r}}=-0.63 \mathrm{~V}$ vs SCE, $E_{2 \mathrm{r}}=-0.70 \mathrm{~V}$ vs SCE, $\alpha=0.5, k_{\mathrm{s}}$ $=1.0 \mathrm{~cm} / \mathrm{s}$; oxidation reaction $E_{1 \mathrm{o}}=+1.21 \mathrm{~V}$ vs SCE, $\alpha=0.5, k_{\mathrm{s}}=$ $0.0035-0.05 \mathrm{~cm} / \mathrm{s}, k_{\mathrm{f}}=0.1 \mathrm{~s}^{-1}$.

out of the plane of the hydrocarbon, and substituents on the $N$-phenyl thus cause only small effects. Structures and energies based on molecular orbital calculations are discussed in a later section. Thus, the redox behavior of the diimide molecules is not affected significantly by $N$-substituents, indicating little contribution of these to the HOMO and LUMO. With extension of the aromatic system, the oxidation of the diimide compound becomes easier. Second irreversible oxidation waves for the PDI, TDI, and QDI are also observed at more positive potentials, corresponding to the oxidation reaction of the radical cation to a reactive dication.

Digital Simulation for Electrochemical Reactions of TDI and QDI. As shown in Figure 2, the height of the reduction peak for TDI and QDI is almost double that of the oxidation peak. We assumed above that two 1e transfer processes occur within a very narrow potential range and that the reduction peaks are superimposed. Digital simulation of the CVs, using the proposed reduction and oxidation mechanisms in Schemes 1 and 2, was carried out and compared with the experimental results. This allowed an estimate of the potentials of the two superimposed reduction peaks. In performing the digital simulations, it is necessary to assume rate constants for the heterogeneous electron-transfer reactions $\left(k^{\circ}\right)$ and compare the curves to experimental data corrected for uncompensated Ohmic drop. 

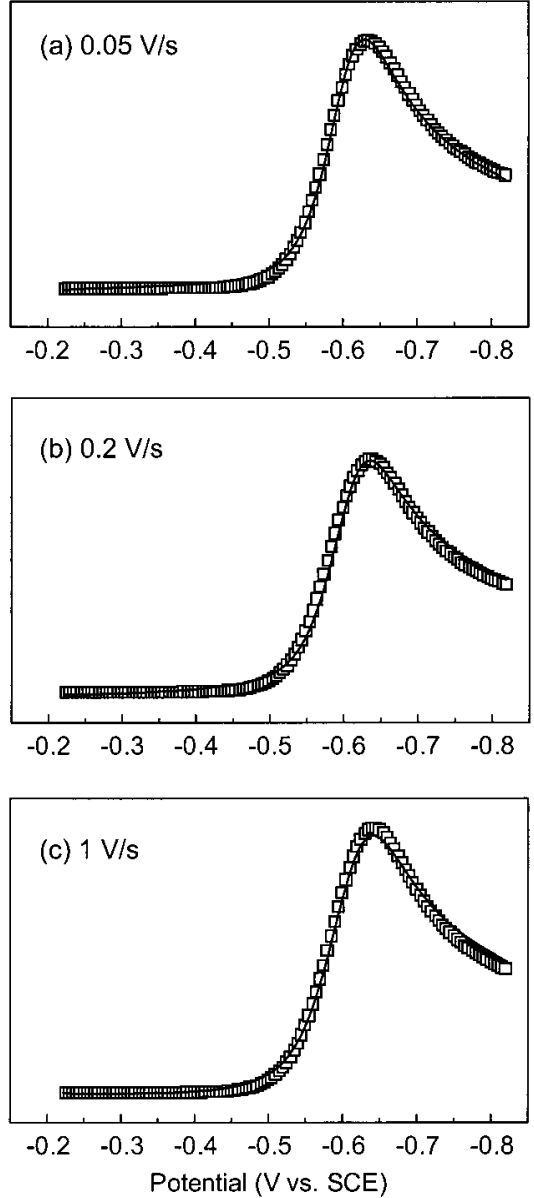

Figure 4. Scan rate variations of cyclic voltammograms by the experimental ( - ) and digital simulations ( $\square$ ) of $0.15 \mathrm{mM}$ QDI in $\mathrm{CHCl}_{3} /$ $\mathrm{CH}_{3} \mathrm{CN}(4: 1, \mathrm{v} / \mathrm{v})$, (electrolyte: $\left.0.1 \mathrm{M} \mathrm{TBAPF}_{6}\right)$ : (a) $=0.05$, (b) $=$ 0.2 , and $(\mathrm{c})=1 \mathrm{~V} / \mathrm{s}$ at a $3.4 \mathrm{~mm}$ diameter $\mathrm{Pt}$ electrode. The experimental data were corrected for Ohmic drop. Simulation parameters: reduction reaction $E_{1 \mathrm{r}}=-0.58 \mathrm{~V}$ vs SCE, $E_{2 \mathrm{r}}=-0.62 \mathrm{~V}$ vs SCE, $\alpha=0.5, k_{\mathrm{s}}=0.5 \mathrm{~cm} / \mathrm{s}$.

However, one can only say that the $k^{\circ}$ values are large, i.e., $\geq 1$ $\mathrm{cm} / \mathrm{s}$, since the waves are near those expected for Nernstian response and the measured $k^{\circ}$ values are very sensitive to uncompensated resistance.

The scan rate dependence of the reduction and oxidation current peaks of TDI showed a linear relationship between $i_{\mathrm{pc}}$ and $i_{\mathrm{pa}}$ and $v^{1 / 2}$ at scan rates up to $20 \mathrm{~V} / \mathrm{s}$, indicating diffusion control. For QDI, however, at scan rates above $5 \mathrm{~V} / \mathrm{s}$, the data for the reduction deviated from the line, indicating, perhaps, quasi-reversibility (results for TDI and QDI are given in the Supporting Information). Experimental and simulated voltammograms at different scan rates are shown in Figures 3 and 4. For TDI, the theoretical and experimental voltammograms match well for the reduction wave over the scan rate range from 0.2 to $20 \mathrm{~V} / \mathrm{s}$. For the oxidation, however, there are small deviations, especially at lower scan rates. To obtain a satisfactory fit to the observed cyclic voltammogram, a decomposition reaction of the TDI radical cation was taken into consideration. The rate constant for this reaction was assumed to be $0.1 \mathrm{~s}^{-1}$. At high scan rates, such as $v=20 \mathrm{~V} / \mathrm{s}$ (Figure 3c), the simulation was not affected by this reaction. Some deviation in this wave may also arise from failure to consider the effect of the second oxidation wave in the simulations. The simulation allows one to estimate the first and second reduction potentials, $E^{\circ}{ }_{1 \mathrm{r}}$ and $E_{2 \mathrm{r}}^{\circ}$, as -0.63 and $-0.70 \mathrm{~V}$ vs SCE, respectively.

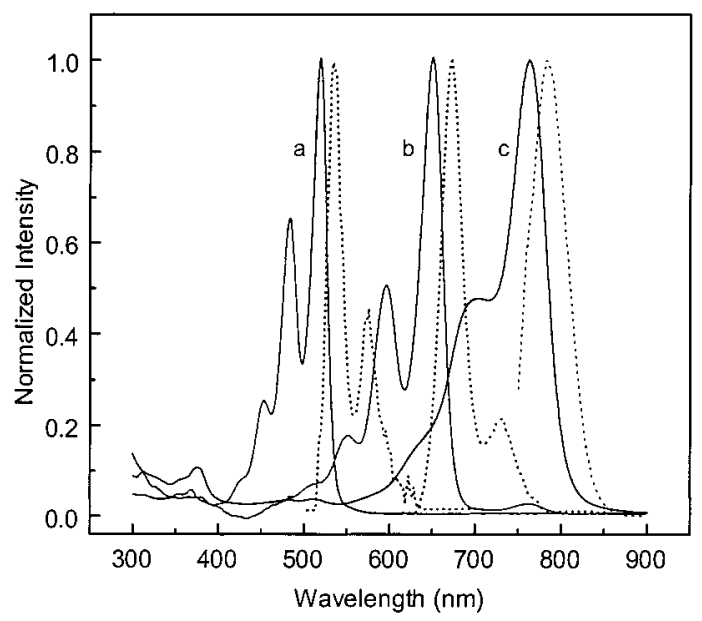

Figure 5. Normalized absorption $(-)$ and fluorescence spectra $(\cdots)$ of (a) $1.0 \times 10^{-5} \mathrm{M}$ PDI-1, (b) $1.0 \times 10^{-5} \mathrm{M}$ TDI, and (c) $1.0 \times 10^{-5}$ $\mathrm{M}$ QDI in $\mathrm{CH}_{3} \mathrm{Cl} / \mathrm{CH}_{3} \mathrm{CN}(3: 2, \mathrm{v} / \mathrm{v})$.

For QDI, the two 1e reduction potentials are closer than for TDI. To avoid any uncertainty caused by other parts of the CV, only the reduction wave was simulated. As mentioned above, the reduction of QDI can be treated as Nernstian only for scan rates below $5 \mathrm{~V} / \mathrm{s}$; simulations for these were carried out (Figure $4)$. The potentials of the two 1e reduction waves were given as -0.58 and $-0.62 \mathrm{~V}$ vs SCE, respectively.

The equilibrium constant for the comproportionation reaction $^{20}$

$$
\mathrm{R}+\mathrm{R}^{2-}=2 \mathrm{R}^{-}
$$

for formation of the radical anion $(K)$ can be calculated by

$$
\log K=\left(E_{2 \mathrm{r}}^{\circ}-E_{1 \mathrm{r}}^{\circ}\right) / 0.059=\Delta E_{\mathrm{r}}^{\circ} / 0.059
$$

The $K$ values are listed in Table 1 . The difference between the first and second reduction potentials $\left(\Delta E^{\circ}\right.$ r) provides a measure of the thermodynamic stability of the radical anion. For PI and PDI, the values of $K$ are quite large, suggesting good stability of the radical anions. The much smaller $K$ values for TDI and QDI imply facile reduction, low concentrations of radical ions, and low ECL intensities.

UV-Vis Spectroelectrochemistry and Photoluminescence. The absorption and emission spectra of PDI-1, TDI, and QDI are shown in Figure 5 (see also ref 2f). PDI-1 exhibits maxima at 521 and $536 \mathrm{~nm}$ in the absorption and fluorescence spectra, respectively. PDI- 2 and 3 closely resemble PDI-1 in both fine structure of the absorption and fluorescence, and location of the maxima, indicating little sensitivity to the $N$-substituents in the HOMO and LUMO of the diimide compound. TDI shows maxima in the absorption and fluorescence red-shifted from PDI at wavelengths of 650 and $673 \mathrm{~nm}$, respectively, while those of QDI reach the near-IR region with wavelengths of 762 and $783 \mathrm{~nm}$, respectively. The photoluminescence is discussed in detail elsewhere. ${ }^{2 f}$ The lowest ground-state absorbance in the $\mathrm{UV}-$ vis region and the $\mathrm{S}_{1}-\mathrm{S}_{0}$ fluorescence emission of the diimide species shifts to longer wavelengths with increasing $\pi$-conjugation. As additional aromatic rings are added to the diimide system, additional bonding and antibonding levels are introduced with a resulting reduction of the energy of the lowest $\pi \rightarrow \pi^{*}$ transition. This trend is also reflected by the decrease of the potential differences of the first oxidation wave and the first reduction wave $\left(\Delta E^{\circ}{ }_{\text {or }}\right)$ as the $\pi$-conjugated system is

(20) Michaelis, L. Chem. Rev. 1935, 16, 243 


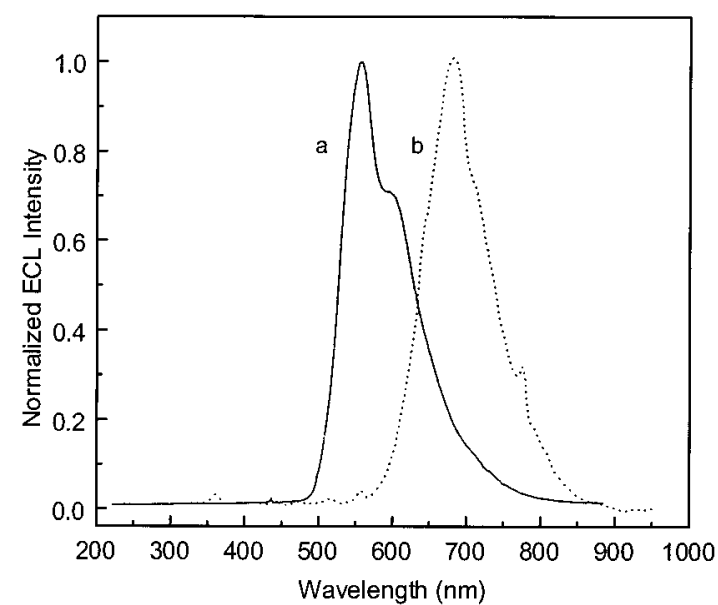

Figure 6. Normalized ECL spectra of (a) $8.0 \times 10^{-4} \mathrm{M}$ PDI-2 in $\mathrm{CHCl}_{3} / \mathrm{CH}_{3} \mathrm{CN}(\mathrm{v} / \mathrm{v}, 3: 2)$ and (b) $2.0 \times 10^{-4} \mathrm{M} \mathrm{TDI}$ in $\mathrm{CHCl}_{3} / \mathrm{CH}_{3} \mathrm{CN}$ $(4: 1, \mathrm{v} / \mathrm{v})$. The potential was stepped (a) from -0.65 to $+1.80 \mathrm{~V}$ and (b) from -0.80 to $+1.40 \mathrm{~V}$. The exposure time was $15 \mathrm{~min}$ (electrolyte: $0.1 \mathrm{M} \mathrm{TBAPF}_{6}$ ).

extended (Table 1), since this potential difference is also a measure of the HOMO-LUMO energy gap.

The UV-vis spectra of PDI-1 and TDI during reduction under potentiostatic control are shown in Figures S2 and S3 in the Supporting Information. The spectra of PDI-1 during electrolysis at $-0.60 \mathrm{~V}$ show the growth of new absorbance peaks at $678,696,705,761$, and $791 \mathrm{~nm}$, which are attributed to the formation of the radical anion. The radical anion forms are stable and have higher absorbances in the visible and IR regions than the corresponding neutral forms. Further reduction of PDI- 1 at $-0.80 \mathrm{~V}$ gives rise to the growth of the dianion peaks at 530, 564, and $596 \mathrm{~nm}$. These results are consistent with the UV-vis data for reduced PDI-3 previously reported. ${ }^{14,19,21}$ PDI-1 can be reversibly cycled among the neutral (yellow), radical anion (green), and dianion (violet) forms. For TDI, an absorbance appears at around $900 \mathrm{~nm}$ when the reduction is carried out at $-0.65 \mathrm{~V}$. No new peaks were observed in the UV-vis region when QDI was reduced at -0.6 V.

Electrogenerated Chemiluminescence. The PDI compounds are good candidates for ECL because of their stable radical ions and high fluorescence efficiencies. When a Pt working electrode immersed in a solution of $\mathrm{CHCl}_{3} / \mathrm{CH}_{3} \mathrm{CN}(3: 2, \mathrm{v} / \mathrm{v})$ containing PDI-2 ( $\sim 0.8 \mathrm{mM})$ was pulsed between the compound's first oxidation and reduction waves, ECL emission was produced by the annihilation reaction. The ECL spectrum (Figure 6a) was in the same region as the photoluminescence (PL) spectrum with a maximum at $555 \mathrm{~nm}$ and a shoulder around $600 \mathrm{~nm}$. The ECL spectrum of $0.2 \mathrm{mM}$ TDI in $\mathrm{CHCl}_{3} / \mathrm{CH}_{3} \mathrm{CN}(4: 1, \mathrm{v} / \mathrm{v})$ (Figure 6b) shows an emission maximum at $679 \mathrm{~nm}$. The ECL emissions from both PDI and TDI have slightly different shapes and maxima compared to their fluorescence spectra. The PL and ECL spectra should be identical, since the same singlet state is responsible for the emission in both cases. The slight redshift and change in relative peak heights of the ECL spectra can be explained by self-absorption at the shorter wavelengths (an inner-filter effect) in the ECL solution, which was more concentrated than the solutions used for fluorescence measurements. The ECL spectra in Figure 6 also do not exhibit the fine structure shown in the fluorescence spectra (Figure $5 \mathrm{~b}$ ) because $(21)$
6692.

(21) Ford, W. E.; Hiratsuka, H.; Kamat, P. V. J. Phys. Chem. 1989, 93 ,
Table 2. Energies Available in the Annihilation Reactions and Needed To Generate Excited Singlet Forms

\begin{tabular}{lccc}
\hline & $-\Delta G_{\text {ann }}^{\circ}(\mathrm{eV})^{a}$ & $-\Delta H_{\text {ann }}^{\circ}(\mathrm{eV})$ & $E_{\mathrm{s}}(\mathrm{eV})^{b}$ \\
\hline PDI-1 & 2.11 & 2.01 & 2.31 \\
TDI & 1.75 & 1.65 & 1.84 \\
QDI & 1.40 & 1.30 & 1.58 \\
\hline
\end{tabular}

${ }^{a}$ Obtained on the basis of the difference between half-wave potentials of first oxidation and first reduction peaks in CV. ${ }^{b}$ Calculated from the highest energy emission peak in fluorescence spectrum.

of the lower resolution of the spectrometer used to measure the ECL.

The relative ECL efficiency ( $\phi_{\mathrm{ECL}}$ ) was measured using Ru(bpy) ${ }_{3}{ }^{2+}$ as the reference standard $\left(\phi_{\mathrm{ECL}}\right.$ of $\mathrm{Ru}(\mathrm{bpy})_{3}{ }^{2+}$ taken as 0.05 in $\mathrm{MeCN}$ at $25^{\circ} \mathrm{C}$ for the annihilation reaction). ${ }^{22}$ The values are around 0.04 and 0.03 for PDI- 2 in $\mathrm{CHCl}_{3} / \mathrm{MeCN}$ $(3: 2, \mathrm{v} / \mathrm{v})$ and TDI in $\mathrm{CHCl}_{3} / \mathrm{MeCN}(4: 1, \mathrm{v} / \mathrm{v})$, respectively. The ECL of QDI was much weaker than PDI and TDI, and the spectrum could not be obtained using the CCD camera. We could only detect the undispersed ECL signal with a photomultiplier.

For both ECL and fluorescence spectra, the singlet is the emitting state. The energy available in the radical cation/radical anion annihilation reaction is given (in $\mathrm{eV}$ ) by ${ }^{10}$

$$
-\Delta H^{\circ}{ }_{\text {ann }}=-\Delta G^{\circ}{ }_{\text {ann }}-T \Delta S^{\circ} \approx\left(E_{1,0}^{\circ}-E_{1, \mathrm{r}}^{\circ}\right)-0.1 \mathrm{eV}
$$

$\Delta G^{\circ}$ ann can be obtained from the difference between the standard potentials of the first oxidation and first reduction waves in the cyclic voltammogram, yielding the values for the compounds studied here and listed in Table 2. The energy for the first excited singlet generation, $E_{\mathrm{S}}$, was obtained from the emission spectrum. For ECL, via the S-route, the following equation must be satisfied:

$$
-\Delta H_{\mathrm{ann}} \geq E_{\mathrm{s}}
$$

Thus, in an energy-sufficient system, the energy provided by the annihilation reaction is large enough to produce a singlet directly. Table 2 clearly shows that, for the diimide compounds studied in this paper, the energy supplied by the ion-annihilation reaction is smaller than that required for direct production of the singlet state. In these energy-deficient systems, the ECL cannot undergo the S-route as expressed by eqs $1-4$. However, the singlet can be produced via the T-route (eqs 5 and 6), where the annihilation reaction produces a triplet, and the luminescent singlet state is formed via triplet-triplet annihilation. ${ }^{10}$ The proposed T-route involves the inefficient triple-triple annihilation process, which results in the relatively low ECL efficiency.

There are several reasons for the much lower ECL efficiency of QDI besides the inefficient T-route. First, as shown in Table 1 , the value of $K$ for QDI is very small, suggesting much poorer stability of the QDI radical anion. When the Pt electrode is pulsed to generate radical cations and anions stepwisely, the disproportionation of $\mathrm{QDI}^{\bullet-}$ will greatly reduce the ECL efficiency. Second, the photoluminesence efficiency of QDI is low, $\sim 0.05,{ }^{2 \mathrm{f}}$ and its emission band lies in the near-IR region, where excited states are easily quenched.

Molecular Orbital Calculations. To correlate the observed electrochemical behavior of this series of compounds with their molecular structure and to obtain a better understanding of the effect of core size on the spacing of the two reduction waves, molecular orbital calculations were undertaken to examine

(22) Wallace, W. L.; Bard, A. J. J. Phys. Chem. 1979, 83, 1350. 
Table 3. Selected Structural Data for the Various $N$-Substituents in the PDI Species

\begin{tabular}{|c|c|c|c|c|}
\hline \multirow[b]{2}{*}{ substituent } & \multicolumn{2}{|c|}{$\begin{array}{l}\text { bond angle of } \\
\text { atoms (deg) }\end{array}$} & \multicolumn{2}{|c|}{$\begin{array}{l}\text { torsion angle of } \\
\text { atoms (deg) }\end{array}$} \\
\hline & $1,4,5$ & $1,4,6$ & $1,2,4,5$ & $1,3,4,6$ \\
\hline $\begin{array}{c}\mathrm{R} 1=\mathrm{R} 4=\text { methyl, isopropyl, } \\
\text { tert-butyl; } \mathrm{R} 2=\mathrm{R} 3=\mathrm{H}\end{array}$ & $\sim 118.8$ & $\sim 118.8$ & $\sim 90$ & $\sim 90$ \\
\hline $\begin{array}{l}\mathrm{R} 1=\mathrm{R} 3=\text { tert-butyl } \\
\quad \mathrm{R} 2=\mathrm{R} 4=\mathrm{H}\end{array}$ & $\sim 123.9$ & $\sim 114.5$ & $\sim 95.3$ & $\sim 84.7$ \\
\hline
\end{tabular}

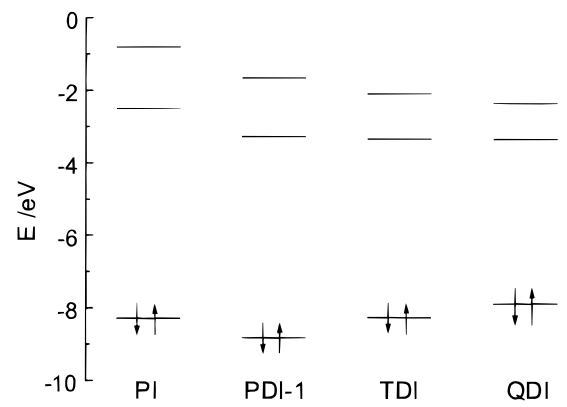

Figure 7. Molecular orbitals calculated with PM3.

orbital energies and charge distributions. First, the structure of each molecule was geometrically optimized using the MM+ force field to find the structure of lowest energy. In all cases, the diimide core was found to be planar, consistent with the structure that would yield the largest resonance stabilization. The $N$-substituents, i.e., the phenyl rings or alkyl groups are located in a plane that is essentially perpendicular to the diimide core. Several bond angles and torsion angles illustrating this are listed in Table 3. With PDI-3, the $N$-phenyl ring is twisted a bit because of the steric hindrance caused by the unsymmetrical substituents. The general lack of interaction of the

(a)

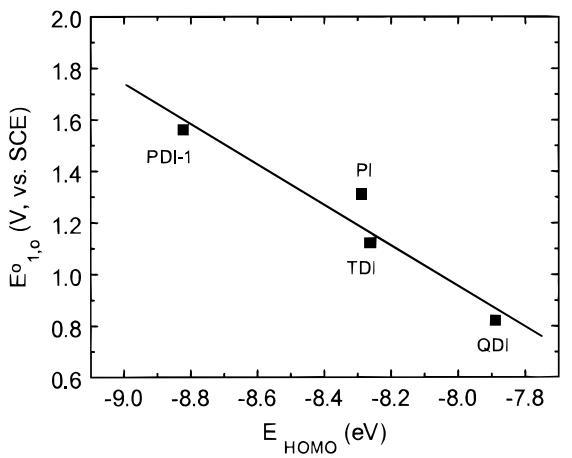

(b)

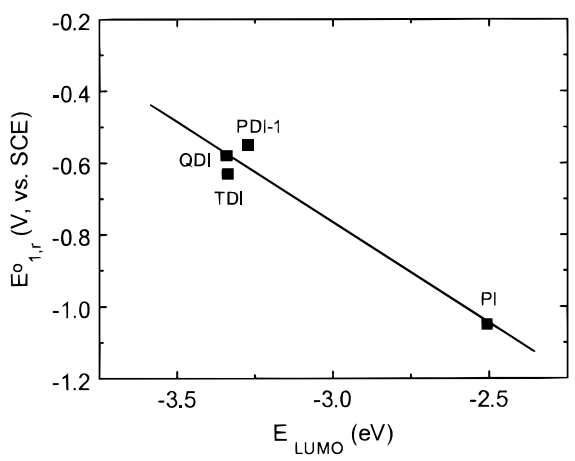

$N$-substituents with the core in the PDI series is consistent with the rather small differences in electrochemical potentials for oxidation and reduction when this substituent is changed.

The calculated (PM3) energies of the HOMOs and LUMOs of the parent compounds of this series are shown in Figure 7. The oxidation of these compounds should correlate with the energies of the HOMOs (Figure 8a). The addition of a second imide group to PI to form PDI results in a decrease in the HOMO energy, consistent with the more difficult oxidation of PDI. Within the diimides, extension of the aromatic fused rings results in an increase in the HOMO energy, again consistent with the observed less positive potentials of electrochemical oxidation of TDI and QDI compared to PDI.

The reduction of the compounds should correlate with the location of the LUMO. The remarkably lower energies of the LUMOs of the diimide compounds compared to PI are also consistent with the observed potentials for reduction (Figure $8 \mathrm{~b}$ ). The differences between the LUMO and HOMO of a given molecule are also in good agreement with the trends seen in $\Delta E^{\circ}$ or and the location of the spectral adsorption and emission bands (Figure 8c). Of particular interest is the merging of the first and second reduction waves with the increase in the size of the aromatic core. This can be understood from the electron distribution in the parent, radical anion, and dianion and the relative splitting of the first and second LUMOs. The charge distribution at each atom was calculated for each diimide and its reduced forms. The electronic charge is largely located at the carbonyl oxygen atoms (Supporting Information Table S1), with additional charge distributed over the connecting aromatic fused ring system. The potentials of the reduction steps are affected by the locations of the LUMOs. The reduction to the radical anion occurs by addition of an electron to the lowest LUMO. It is known from studies of many aromatic species that

(c)

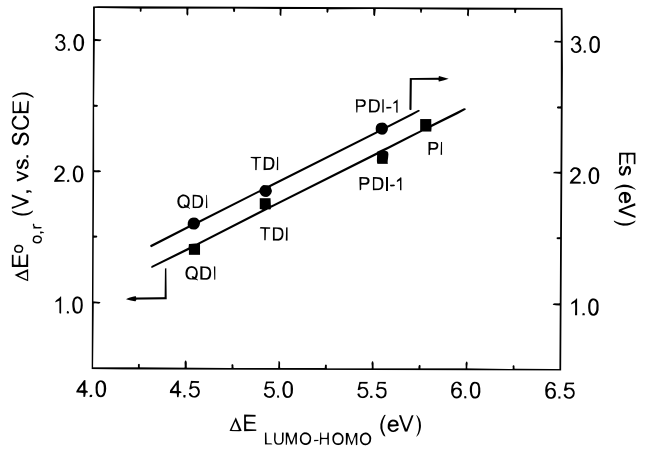

(d)

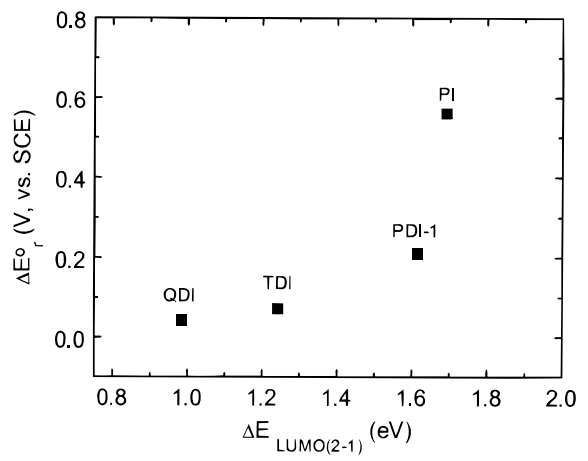

Figure 8. Correlation of experimental data with molecular orbital calculation results: (a) oxidation potential versus HOMO energy, (b) reduction potential versus LUMO energy, (c) potential difference between the first oxidation and first reduction waves versus energy difference between HOMO and LUMO, and (d) potential difference between the first and second reduction waves versus energy difference between the first and second LUMO. 
addition of a second electron to the same orbital, corrected for better solvation of the dianion, results in a potential difference of about $0.5-0.6 \mathrm{~V} .{ }^{23}$ This results from the considerable repulsion energy for two electrons in the same orbital (pairing energy). Addition of a second electron into the next LUMO, equivalent to the addition of an electron into the second imide group, can involve a lower energy. Although this orbital is not degenerate with the lowest LUMO, when one takes into account the larger stabilization of the dianion by solvation and ion pairing, one can rationalize the very close spacings of the two reduction waves in TDI and QDI. The trend in $\Delta E_{\mathrm{r}}^{\circ}$ values for the series follows the observed decrease between the two LUMOs (Figure 8d).

The question of the extent of interaction of two identical electroactive groups on the same molecule and its effect on the voltammetric response has been the subject of a number of studies. ${ }^{24,25}$ Strong interaction results in a large splitting between the reduction waves on the electroactive moieties, while no interaction produces a single wave for the simultaneous reduction of both, with the appearance of a single $1 \mathrm{e}$ wave representing the statistical spacing of the $E^{\circ}$ 's of $(2 R T / n F) \ln 2$ $\left(36 \mathrm{mV}\right.$ at $25^{\circ} \mathrm{C}$ ). When the electroactive groups are coupled with a saturated chain, even as short as $-\mathrm{C}_{2} \mathrm{H}_{4}-$, the groups show little or no interaction. Polyene chains show interactions over longer distances. Studies of groups such as ferrocene, viologen, or $\mathrm{Ru}(\mathrm{bpy})_{3}{ }^{2+}$ linked by polyenes of different length have shown that the interaction decreases with the number of interposed double bonds, $n$. Typically, there is little interaction when $n=5$ or $6 .{ }^{26}$ If the chain is a polymethine-type, where solitonic behavior is possible, interactions over longer distances (e.g., $n \geq 9$ ) can occur. ${ }^{27}$ A chain that includes aromatic moieties may show smaller interactions over similar distances, e.g.,

(23) Peover, M. E. In Electroanalytical Chemistry; Bard, A. J., Ed.; Marcel Dekker: New York, 1967; Vol. 2, Chapter 1.

(24) Ammar, F.; Savéant, J. M. J. Electroanal. Chem. 1973, 47, 115.

(25) Flanagan, J. B.; Margel, S.; Bard, A. J.; Anson, F. C. J. Am. Chem. Soc. 1978, 100, 4248 and references therein.

(26) (a) Ribou, A.-C.; Launay, J.-P.; Sachtlebeu, M. L.; Li, H.; Spangler, C. W. Inorg. Chem. 1996, 35, 3735. (b) Benniston, A. C.; Goulk, V.; Harriman, A.; Lehn, J.-M.; Marczinke, B. J. Phys. Chem. 1994, 98, 7798 and references therein. because of charge localization on these. ${ }^{28}$ The work described here suggests similar decreased interactions across rigid aromatic units.

\section{Conclusions}

The electrochemical behavior of several diimide compounds (PDI, TDI, and QDI) was examined and compared to that of the parent imide, PI. While the $N$-substituents have little influence on the electrochemical behavior, a large effect is noted with extension of the aromatic core between the imide groups. As the core size increases, oxidation becomes easier and the potentials for the two reduction steps become closer, so that for TDI and QDI only a single overlapped 2e wave is seen. Thus the tendency for the radical anion to disproportionate follows the series QDI > TDI $\gg$ PDI. These results can be rationalized by molecular orbital calculations.

The adsorption and emission spectra exhibit a significant red shift from PDI to the near-IR with QDI that reflects orbital energy changes. ECL emission is observed at a Pt electrode for these systems, when the potential is pulsed between the first oxidation and first reduction waves. The ECL efficiency is smaller for TDI and QDI, probably because of the extensive disproportionation of the radical anions and lower fluorescence quantum efficiencies.

Acknowledgment. Funding by the Robert A. Welch Foundation, Texas Advanced Research Program, and IGEN Inc. is gratefully acknowledged.

Supporting Information Available: Scan rate dependence for cyclic voltammetry of TDI and QDI, UV-vis spectra for reduction of PDI-1 and TDI, and calculated fractional electron densities (PDF). This material is available free of charge via the Internet at http://pubs.acs.org.

\section{JA984188M}

(27) (a) Tolbert, L. M.; Zhao, X.; Ding, Y.; Bottomley, L. A. J. Am. Chem. Soc. 1995, 117, 12891. (b) Tolbert, L. M. Acc. Chem. Res. 1992, 25,561 .

(28) See, for example: Tiemann, B. A.; Cheng, L.-T.; Marder, S. R. J. Chem. Soc., Chem. Commun. 1993, 9, 735. 